\title{
Notas sobre o fenômeno depressão a partir de uma perspectiva analítico-comportamental
}

A depressão passa a existir a partir de uma interação social dada e, desse modo, pode ser compreendida como um fenômeno cuja dimensão maior ou primária é um processo de interação social. Assim, é multidefinida e sempre resultado de uma nomeação regulada pela comunidade.

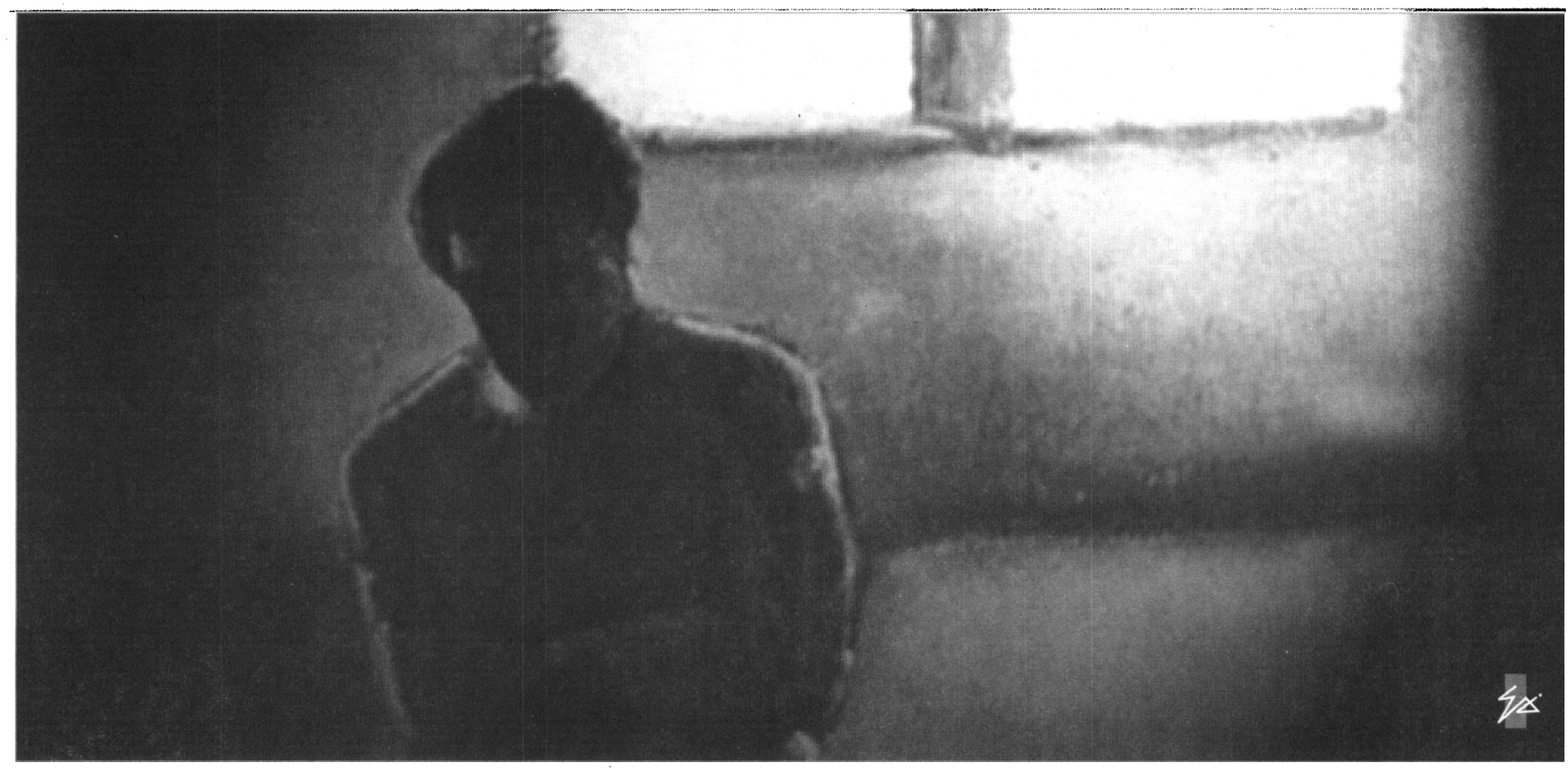

Simone Neno Cavalcante

Psicóloga da Clínica de Psicologia/UFPA e aluna do Curso de Mestrado em Psicologia: Teoria e Pesquisa do Comportamento. Universidade Federal do Pará. Trabalho desenvolvido como atividade deste Curso de Mestrado.
Vários estudos sobre a depressão enfatizam a sua alta incidência e prevalência entre a população em geral ( por exemplo, Casey, 1994; Hollon e Carter, 1994; Turner, 1994). Esses dados justificam o expressivo volume de pesquisas encontrado na literatura, dentre as quais há exemplos voltados à etiologia (Kendler, Neale, Kessler, Heath e Eaves, 1994; Pardoen, Bauwens, Tracy, Martin e Mendlewicz, 1993), à investigação de estratégias de tratamento (Beach, Whisman e O'Leary, 1994; Harris, 1994; Koerner, Prince e Jacobson, 1994; Nishith, Hearst, Mueser e Foa, 1995; Spangler, Simons e Thase, 1997) e em menor escala, estudos dedicados a medidas de follow-up (Piccinelli e Wilkinson, 1994; Surtees e Barkley, 1994).

Este trabalho aborda a depressão de acordo com o referencial teórico da análise do comportamento e, a partir do trabalho de Dougher e Hackbert (1994), discute alguns sintomas desse fenômeno em relação a conceitos e princípios comportamentais estabelecidos, sem a intenção de avaliar estratégias de tratamento.

Basicamente, argumenta-se que no âmbito de uma perspectiva analíticocomportamental a depressão deve ser entendida como um conjunto complexo de comportamentos; um padrão de interação com o ambiente. Por essa ótica, não há como compreender o comportamento depressivo sem recorrer a uma análise funcional do mesmo em relação ao contexto particular no qual ocorre. 


\section{I- Depressão: Etiologia e Tratamento.}

Tem sido argumentado que no tratamento da depressão, embora coexistam alguns achados contraditórios, "as conclusōes mais geralmente aceitas são as de que uma combinação de terapia cognitiva e medicação antidepressiva parece ser melhor que uma das alternativas isoladamente, que são comparáveis e melhor do que placebo ou o controle de tratamento mínimo" (Dougher e Hackbert, 1994, p.321).

Por outro lado, Antonuccio, Danton e De Nelsky (1995) informam, a partir de pesquisas conduzidas nas áreas de psiquiatria e psicologia, que a terapia (particularmente a cognitivo-comportamental) tem se mostrado "pelo menos tão efetiva quanto a medicação no tratamento da depressão, mesmo que severa"(p.12). Argumentam que apesar das evidências da eficácia das intervençōes psicológicas e dos riscos e efeitos colaterais das drogas, nos Estados Unidos os medicamentos antidepressivos têm sido 0 recurso mais utilizado no tratamento da depressão. Sustentam que esta adesão pode ser explicada, em parte, pelo marketing efetivo em prol dos medicamentos, pelas altas taxas de reembolso de seguro-saúde, que privilegiam intervençōes médicas em detrimento da psicoterapia (geralmente $80 \%$ e $50 \%$, respectivamente) e pela influência exercida por algumas organizaçōes de ajuda para a adoção de um tratamento aparentemente mais rápido e efetivo.

A propagação da suposta eficácia da farmacoterapia tem impulsionado um grande número de pesquisas (por exemplo, Casey, 1994; Preskorn, 1994; Thompson, 1994) voltadas para a descoberta de novos medicamentos que, agindo de maneira mais seletiva, diminuiriam os efeitos colaterais adversos associados aos tratamentos tradicionals, evitando, inclusive, as conseqüências nocivas das drogas sobre mecanismos que não são essenciais para a resposta antidepressiva. Iniciativas dentro dessa linha são as pesquisas com os inibidores seletivos de recaptação de serotonina (ISRS)' em relação aos inibidores da monoaminoxidase e aos antidepressivos tricíclicos.

Ainda que seja admitido que as atuais linhas de pesquisas sobre a depressão têm gerado da 'os úteis para efeito de intervençōes de tratame too, também é reconhecido que a literatura nìo provê uma explicação adequada para a etiologia e tratamento do fenômeno de um ponto de vista analítico-comportamental. A ênfase recai nos processos biológicos e cognitivos e não nas relaçōes ambientecomportamento (cf. Dougher e Hackbert, 1994). De uma perspectiva analíticocomportamental, dois aspectos desses modelos são especialmente problemáticos: a noção de causação interna do comportamento e a definição de depressão pelos sintomas.

\section{I.1. A causação interna do comportamen- to: a busca de fatores psicológicos subjacentes.}

A crença na determinação do comportamento por eventos interiores está amplamente disseminada em nossa cultura e é não raro sustentada pela própria psicologia.

De fato, na cultura ocidental, causas internas têm sido historicamente legitimadas como as explicaçōes mais plausiveis para o comportamento (cf. Skinner, 1974). Um exemplo contemporaneamente ilustrativo de apelo a explicaçōes internalistas do comportamento é a terapia cognitivo-comportamental, que reserva às estruturas cognitivas status de entidades causais. No caso da depressão, as abordagens cognitivas tentam modificar crenças e expectativas irracionais, desenvolvidas a partir de experiências prévias (ver, por exemplo, Beck, Rush, Shaw \& Emery 1979/1982; Jarrett e Nelson, 1987). Esse entendimento leva à busca de processos psicológicos subjacentes internos que seriam determinantes do comportamento, reforçando a crença de que pensamentos são causas de comportamento. Este modo de análise seria, portanto, incompatível com o princípio de determinação externa do comportamento.

\section{2. A visão cultural dos problemas psicológicos: a depressão definida pelos sintomas.}

Ao lado de outros fatores, múltiplas influências culturais podem contribuir para a depressão como, por exemplo, a crescente alienação e estresse presentes nas sociedades industriais e crenças culturais acerca do comportamento humano. Neste último caso, a crença de que eventos internos são as causas do comportamento e o conceito de saúde psicológica, propagado pela mídia -que reúne elementos como garantia de recursos econômicos suficientes, prazer e relaçōes humanas tranqüilas e ausêncla de sentimentos e pensamentos perturbadores- seriam particularmente úteis para uma melhor compreensão da depressão (Dougher e Hackbert, 1994).
'Os inibidores de recaptał serotonina surgiram do $c c$ de que a neurotransmissá serotonina seria fundamei para a resposta antidepre: Assim, a depressäo estarik associada a uma deficiênc funcional de serotonina n. sinapse e à resultante diminuiçào da ativação ds receptor de serotonina no neurônio pós-sináptico. Preskorn (1994) sintetiza complexa série de açōes farmacológicas e alteraçō compensatórias nos mecanismos neurais provocadas pelos efeitos seletivos dos ISRS, que pa resultar em melhor neurotransmissão da serotonina: "A serotonina armazenada em vesiculas neurônio pré-sináptico. Ac liberada, ativa receptores especificos da célula efeto. pós-sináptica. A ativaçāo receptores afeta o neurôni. pós-sináptico através de $u$ sistema segundo-mensage Estes eventos em cascata parecem ser importantes ? modulação do afeto, sono, apetite e impulso sexual, , representam as funçōes $c \epsilon$ prejudicadas durante um episódio de depressāo mai Após ativação do receptor, serotonina é removida da sinapse pela bomba de recaptação, que a transpo volta ao neurônio pré sináptico....OS ISRS inibe bomba de recaptaçāo, o qu aumenta o tempo de

permanência da serotonin sinapse, resultando em $u$. concentração mais alta de serotonina em seu local di o maior periodo de trânsi maior concentração local produz uma alteração na sensibilidade dos receptor sinápticos de serotonina" 70s). Para uma discussāc efeitos nocivos dos inibids seletivos de recaptação de serotonina, ver Antonucci Dantone

De Nelsky (1995). 
Dougher e Hackbert (1994) chamam atenção para o fato de que os "problemas psicológicos" são definidos em grande extensão pela presença de sintomas, freqüentemente traduzidos em termos de sentimentos e pensamentos, a exemplo do sistema de classificação do Manual Diagnóstico e Estatístico de Transtornos Mentals.

o Manual é uma "classificação... que divide [ou categoriza] os transtornos mentais em tipos a partir de um conjunto de critérios com características que os definem"(APA, 1994, p., xxi). Na versāo atual do Manual, o DSM-IV (1994), o foco de interesse está concentrado na descrição e manifestação dos sintomas. Os principais sintomas da depressão estão incluídos sob o título geral de Transtornos Depressivos e incluem humor deprimido, interesse ou prazer diminuído nas atlvidades, distúrbios de apetite (ganho ou perda de peso), distúrbios do sono (Insônia ou hipersonia), uma redução geral do nivel de atlvidade, agitação ou ansiedade, fadiga ou perda de energia, sentimento de inutilidade ou culpa, confusão cognitiva e Ideaçăo suicida. Em função da heterogeneidade das apresentaçōes clínicas, é facultado ao indivíduo apresentar um subconjunto dos Itens derivados de uma lista mais extensa para, assim, ser considerado como integrante de uma determinada categoria.

Diante dos sinals de uma provável patologia, a exemplo da depressão, uma reação típica dos individuos é tentar reprimir ou controlar experiências privadas indesejadas. Os sintomas individuals de depressão são geralmente descritos na literatura como déficits comportamentais, afetivos ou cognittvos, como disposto no sistema categorial adotado pelo DSM IV. A grave restrição ao uso do sistema DSM é a ênfase atribuida à topografia comportamental em detrimento da identificação de relações de contingência. Apesar desse fato, esse tipo de classificação pode ter a sua utilidade testada à medida que aponte para as importantes relaçōes de controle, possibilitada a partir de uma análise funcional ${ }^{2}$, com base em conceitos e princípios comportamentais validados (Hayes e Follette, 1992).

${ }^{2}$ Em um estudo recente Guilhardi e Oliveira (1997) descrevem os passos de uma cuidadosa análise funcional a partir de um caso clínico de depressão.
A visão cultural dos problemas psicológicos surgirla, nesse contexto, como um agravante, uma vez que definida, em grande extensão, pela presença de "sintomas" traduzidos simplesmente por certos sentimentos e pensamentos. Nesse sentldo, um estudo sobre a depressão implica examinar, também, a noção de evento "subjetivo" ou "psicológico" com a qual se está operando, enquanto categoria à qual problemas como a depressão são pertinentes.

\section{II - O Behaviorismo Radical e a Temática da Subjetividade.}

O behaviorismo surgilu no Iníclo do século XX, impondo-se a tarefa de crlar uma disciplina psicológica desvinculada metodologicamente da filosofia, o que significava rejeitar o dualismo filosófico e romper com o método introspectivo.

O behaviorismo radical de Skinner, classificado por Moore (1995) como "uma forma de neobehaviorismo no sentido cronológlco"(p.6), è um empreendimento que se coloca contra qualquer tipo de mentallsmo. Mais do que isso, concebido como a filosofia da clência do comportamento (Skinner, 1974), o behaviorismo radical propōe uma mudança na forma de pensar sobre o homem ao examinar criticamente questōes para as quais a psicologia tradiclonal não tinha, segundo Skinner, oferecido respostas satisfatórias.

\section{II.1. O conceito skinneriano de evento privado.}

O behaviorismo radical admite que dentre as varláveis relacionadas com o comportamento humano algumas estão acessivels apenas a uma pessoa e podem desempenhar um papel importante na determinação do comportamento. Isso não permite que se conclua que os fenômenos subjetivos sejam dotados de propriedades especiais (cf.Moore, 1995). Skinner referiu-se a esses fenômenos como eventos privados, relacionados a condiçōes físicas privadas e a comportamentos encobertos. Em qualquer dos dois casos, não explicam o comportamento; são fenômenos comportamentals adicionais a serem explicados.

Como Moore (1995) ressalta, "esses fenômenos não modulam, necessariamente, todas as formas de atividade manifesta"(p.7). Quando desempenham papel funcional, este só pode ser compreendido à luz da história passada de exposição do indivíduo a certa: contingências de reforçamento. A característic que os distingue dos eventos publicament : observáveis é que eles são os únicos cujo acesso direto só é permitldo ao próprio Individuo. $O$ problema da privacidade resume - se 
para Skinner, num problema de acesso, e não de natureza.

Ao conceber os eventos privados como fenômenos dotados de dimensōes físicas, Skinner admite a possibilidade de que venham a ser examinados cientificamente, ainda que permaneçam inacessíveis a uma observação pública direta. A qualidade de um conceito científico deve ser julgada não pela sua correspondência com referentes públicos como apontado pela versão de operacionismo defendida pelo behaviorismo metodológicomas pelo que permite em termos de interação do cientista com o objeto de sua investigação (cf. Skinner, 1945).

A partir de uma concepção funcional da linguagem, Skinner introduz a privacidade em seu projeto particular de behaviorismo. $\mathbf{O}$ comportamento verbal deveria ser explicado como funçāo de contingências de reforçamento providas por uma comunidade verbal. Nesse caso, a instalação de um repertório autodescri: tivo de eventos privados seria feita pela comunidade verbal que, através de determinadas estratégias, ensinaria o indivíduo a responder discriminativamente a si mesmo.

Skinner sugere quatro estratégias através das quais a comunidade procura tornar possível ao indivíduo o aprendizado de respostas verbais a estímulos privados. No entanto, nenhuma das estratégias sugeridas mostrou-se suficiente para prover a instalação de um repertório verbal confiável a respeito dos estímulos privados. Todas seriam passiveis de erro ou de limitação na sua aplicação, uma vez que a comunidade não tem acesso direto aos eventos privados de um indivíduo (ver, a propósito, Malerbi e Matos, 1992).

As respostas aos estímulos privados nāo parecem diferir das respostas aos acontecimentos públicos ... (mas) o ìnvestigador não pode, de imediato, apontar os estímulos aos quais deve recorrer para a previsão e o controle do comportamento. É possível que este problema eventualmente seja resolvido pela melhoria das técnicas fisiológicas, que tornarão públicos os eventos privados. No campo verbal, por exemplo, se fosse possível dizer precisamente que acontecímentos no ínterior de um organismo controlam a resposta estou deprimido e, especialmente, se pudéssemos produzir esse acontecimento à vontade, poderíamos atingir o grau de previsāo e controle característicos das respostas verbais aos estímulos externos (Skinner, 1957/1992, p.130, Itálico do original).

\section{II.2. (Re) definindo a depressão.}

A palavra depressão, do francês dépression (originária do latìm depressione), é definida no século XVIII como abaixamento (Machado, 1977). Uma definiçāo mais contemporânea (Ferreira, 1986) revela significados que se relacionam tanto à anatomia (achatamento ou cavidade superficial ), quanto à astronomia (distâncla angular, medida sobre um círculo vertical, entre um ponto da esfera celeste abaixo do horizonte e este último; altura negativa) e à economia (sltuação em que os volumes de consumo e de produção per capita e o número de empregados são inferiorec aos normals, havendo recursos econômicos não utilizados ( $\mathrm{Cf} .$, nesta acepç., crise). A palavra

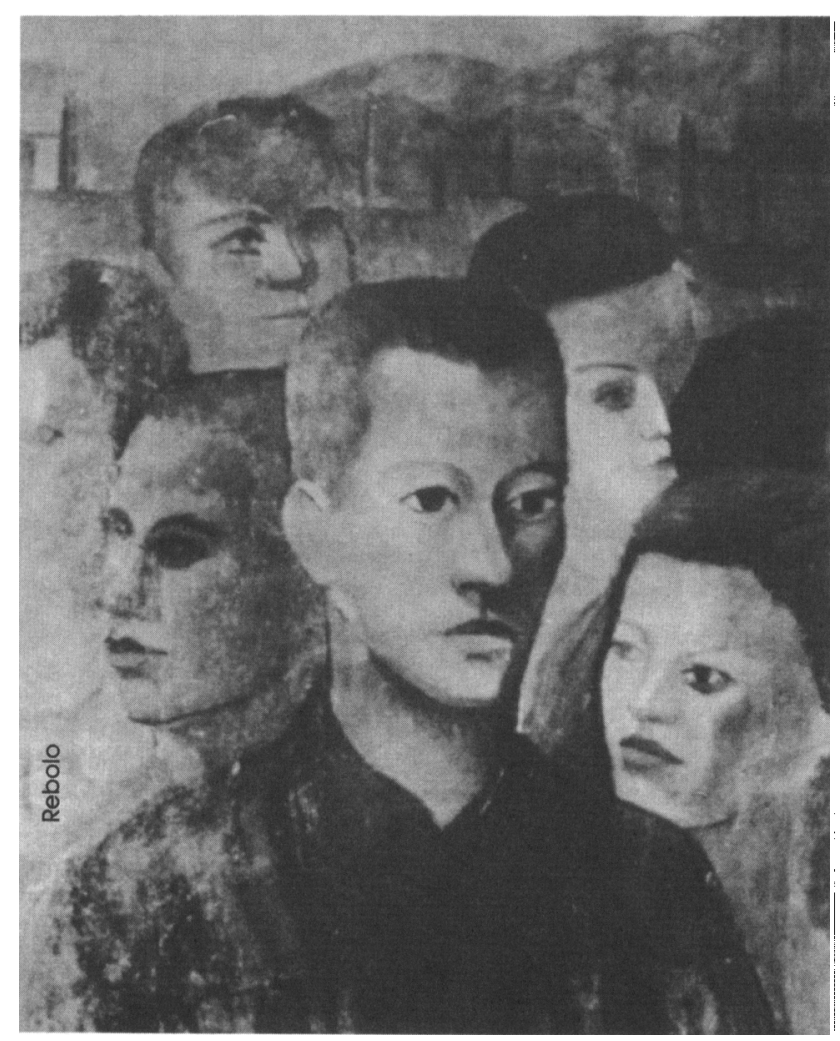

conserva, ainda, o significado original de abaixamento (resultante de pressão ou de peso), além do significado de diminuição e redução; letargia. A definição contemporânea inclui, ainda, o significado da palavra entre a psiquiatria ( distúrbio mental caracterizado por desânimo, sensaçāo de cansaço, e cujo quadro muitas vezes inclui, também, ansiedade em grau maior ou menor) e, finalmente, o sentido figurativo (abatimento físico ou moral), que sugere uma dimensāo físıca e uma "subjetiva". 
Skinner (1989) salienta que todas as palavras usadas para designar sentimentos começaram como metáforas. Assim, depressão, na forma como foi definida pela psiquiatria (e incorporada à linguagem do senso comum), guarda semelhança, de maneira metafórica, com o sentido figurado da palavra e com a forma com que esta foi originalmente concebida (abaixamento). $\dot{E}$, portanto, o abatimento físico e moral; o abaixamento; é o "fundo do poço" que aparece na fala dos deprimidos.

Para o behaviorismo radical, é nas relaçōes com o ambiente externo que devem ser buscadas as explicaçōes para o comportamento, que seria o produto de três tipos de seleçāo: a seleçāo natural (ou filogênese), o condicionamento operante ( ou ontogênese) e a evoluçāo das contingências sociais do comportamento (cultura) que explicam os amplos repertórios característicos da espécie humana. Neste caso (como já foi assinalado), a depressão pode ser melhor descrita como um padrão de interação com o ambiente e, como produto de seleção, antes de ser classificada como patológica, deve ser compreendida a partir da análise das contingências que a mantém:

Como observa Tourinho (1997a), "numa perspectiva comportamental, é apenas a partir de contingências sociais que os indivíduos vêm a reagir de um modo particular a suas condições corporais; as contingências e os modos de reaçāo, por outro lado, são verbais" (p.179, itálico do original). Isso significa dizer que ao considerar as descriçōes de "depressão" de um indivíduo, deve-se levar em conta que: ...antes que um indivíduo interaja com uma comunidade verbal suas condições corporais não são experimentadas como dor, depressão, amor, etc. elas são apenas alteraçōes fisiológicas indiferenciadas para o individuo no corpo de quem ocorrem .... ou seja, o privado enquanto fenômeno psicológico tem uma existência determinada e limitada pelas práticas socials com as quals interagimos .... E como essa interação é predominantemente verbal, é através da análise do fenômeno verbal que podemos vislumbrar um modo de lidar com a privacidade (Tourinho, 1997a, p.180, itálico do original).

Os relatos de eventos privados, dentro de certos limites, podem ocorrer sob controle de estimulações internas associadas aos eventos públicos. Nesse caso particular, a participaçāo do evento interno no controle discriminativo da resposta depende de sua correspondência com condiçōes públicas.
Por exemplo, se alguém chega ao terapeuta e se descreve como deprimido, a condição interna sob controle da qual a resposta é emitida pode ser qualquer uma, variando de indivíduo para indivíduo, e até mesmo para um mesmo indivíduo em diferentes momentos, desde que esteja associada a um padrão de respostas públicas com base no qual a comunidade descreve alguém como deprimido (Tourinho, 1997b, p. 224).

\section{III - Alguns Aspectos da Depressão a partir dos Conceitos e Principios Comportamentais.}

Dougher e Hackbert (1994) analisam alguns padrōes de interação com o ambiente apresentados por indivíduos classificados como deprimidos. Os princípios específicos enfatizados incluem: a) funçōes consequenciais, b) funçōes respondentes, c) funçōes estabelecedoras $\mathrm{e}$ d) processos verbais.

\section{1. Funçōes conseqüenciais.}

Baixa densidade de reforçamento. Ferster (conforme citado por Dougher e Hackbert, 1994) ressaltou que a redução de certos tipos de atividades, acrescida de uma alta incidência de reclamações, choro $\mathrm{e}$ irritabilidade é a característica mais patente do depressivo. A explicação para a baixa taxa de comportamento seria uma escassez relativa de reforçamento. Na avaliação de Lewinsohn e cols. (conforme citados por Dougher e Hackbert, 1994) no entanto, o ponto crítico não seria a densidade de reforçamento em si, mas a taxa de reforçamento positivo contingente à resposta, o que valida a conclusão de que a depressão pode ser gerada quando o reforçamento por não responder é maior que o reforçamento por responder.

A escassez de reforcamento social causada, entre outros fatores, por um repertório social inadequado- tem sido apontada como relevante para o início e manutençāo da depressão. Lewinsohn e Libet e Lewinsohn (conforme citados por Dougher e Hackbert, 1994) têm demonstrado que o comportamento dos depressivos não favorece a obtençào e manutenção da interação social e são geralmente vistos como aversivos e evitados por outros. 
Extinção. Freqüência reduzida ou um nível cronicamente baixo de comportamento pode levar à extinção. Pesquisas conduzidas com animais demonstram que há respostas de depressão quando a extinção geral é introduzida após uma histórla de reforçamento. Diante de um processo de extinção lento e gradual, pode haver dificuldade na identificação da origem da depressão. Entretanto, o mais comum é a procura por tratamento após uma perda importante ( por exemplo, a morte de uma pessoa significativa; o rompimento de um relacionamento afetivo; a perda de um emprego; aposentadoria etc). Ainda que os efeltos de uma perda súbita de reforçamento afetem qualquer pessoa, os individuos com repertório suficiente seriam capazes de encontrar outras fontes de reforcamento. 0 ponto crítico, nesse caso, seria a disponibilidade de repertório adequado para obter fontes alternatlvas de reforçamento. Nesse sentido, o cultivo de uma variedade de fontes de reforçamento e de atividades reforçadoras seria uma boa inoculação contra a depressão (Dougher e Hackbert, 1994).

Punição. A depressão crônica é comum entre os indivíduos com histórias de punição prolongadas e inevitáveis, tais como as associadas a abuso físico e/ou sexual de crianças ou associadas a pais excessivamente críticos e exigentes. O fato seria agravado quando o comportamento defensivo ou retaliatório engendrado pela punição resultasse, também, em punição (Dougher e Hackbert 1994). Os trabalhos sobre desamparo aprendido (ver, por exemplo, Seligmam,1975) sugerem que estimulação aversiva inevitável provoca redução comportamental e interfere no efeito subsequente de contingências de reforçamento. Hunziker (1993) explica que: O estudo do desamparo se destaca pela análise da história passada como um evento crítico na determinaçāo do comportamento presente. Na maioria dos estudos animais, o desamparo tem sido caracterizado pela dificuldade de aprendizagem operante apresentada por sujeitos submetidos previamente a eventos incontroláveis (nāo-contingentes). Via de regra, esses eventos correspondem a estimulos aversivos (geralmeı te choques elétricos) cuja ocorrência independt do comportamento do sujelto. A dificuldade em aprender tem sido avaliada comparando-se o comportamento desses sujeltos frente a contingências operantes (principalmente de fuga ou esquiva) com o comportamento de sujeitos previamente submetidos a choques controláveis ou a nenhum choque: nessa comparação, maiores latências das respostas de fuga/esquiva, ou a não aprendizagem dessas respostas, caracteriza o desamparo.... Diferentes formulações teóricas foram apresentadas para explicar 0 desamparo ... essas hipóteses sugerem que a dificuldade de aprendizagem operante observada nesses estudos é meramente um subproduto da baixa atividade locomotora dos animais e não um processo de aprendizagem emsi.

Entretanto, a hipótese que ganhou malor projeção na análise desse fenômeno não atribui à atlvidade um papel crítico. Segundo alguns autores, os individuos submetidos à incontrolabilidade aprendem que os eventos do meio ocorrem independentemente do seu comportamento e essa aprendizagem interfere na aprendizagem oposta de fuga ou esquiva...Essa hipótese recebeu o mesmo nome do fenômeno que se propōe a explicar (learned helplessness hypothesis) o que gera muitas vezes confusão entre o fenômeno e a sua explicaçāo. Apesar dessa mistura indesejável, esta é a única formulaçāo teórica que analisa o desamparo diretamente como um processo de aprendizagem associativa e não como subproduto de outros processos, análise essa que tem se revelado mais consistente com os dados experimentals que a proposta da inatividade...(p. 491).

Hunziker (1993) argumenta que embora predomine na literatura a idéia de que o desamparo tem se revelado um modelo comportamental útil na pesquisa experimental de depressão, um exame da maioria dos trabalhos produzidos demonstra falta de rigor conceitual e falhas metodológicas (ver, a propósito, Hunzlker, 1982).

Reforçamento de comportamento que evidencia manifestação de sofrimento (reinforcement of distressed behavior).

$\dot{E}$ freqüente entre os indivíduos depressivos uma alta taxa de comportamento de sofrimento, que inclui reclamaçāo, choro e irritabilidade. Ferster ( conforme citado por Dougher e Hackbert, 1994), sustenta que esses são tipos de comportamento de fuga e esquiva mantidos por reforçamento negativo. Expressōes faclais de tristeza, determinadas posturas corporais e queixas, serviriam para reduzir a probabillidade de estımulação aversiva de outros. Esse repertório seria facllmente estabelecido em ambientes multo punitivos. "Além de reduzir a 
estimulação aversiva, o comportamento de sofrimento é, algumas vezes, positivamente reforcado pelo aumento de simpatia e atenção social [contudol, mesmo quando ele aumenta a simpatia a curto prazo...é percebido por outros como sendo aversivo...[sendo evitado pelas pessoas (Dougher e Hackbert, 1994, p. 324). Essa evitação resultaria em remoção da fonte de reforçamento para a pessoa depressiva, cujo resultado, geralmente, implica a exacerbação da depressāo.

\section{III.2. Funçōes respondentes.}

O estado afetivo (sentimentos $\mathrm{e}$ reaçōes emocionais) associado à depressão preclsa ser examinado com cautela, porque é o sintoma diagnóstico primário da depressāo e, vla de regra, a razão primeira que leva os indivíduos à procura de atendimento (Dougher e Hackbert, 1994).

"Em termos comportamentais, reforçamento insuficiente, extinção e punição funcionam como estímulos incondicionados que eliciam um conjunto de respondentes que são denominados de tristeza, frustração e raiva...A afirmação de que essa função respondente não é aprendida, é sustentada pelas reaçōes emocionais de animais colocados em extinção ou expostos à punição"(Dougher e Hackbert, 1994, p. 324).

Reações emocionais associadas à depressão, poderiam gerar sofrimento posterior em ciclo crescente. Esse incremento de reaçōes emocionais levaria a inúmeros sintomas depressivos, amplamente descritos no manual DSM-IV. Através da associação com a estimulação aversiva produzida pela escassez de reforçamento, estímulos discriminativos relevantes (ou qualquer estímulo associado com punição ou reforçamento não disponivel) poderiam, também, desempenhar o papel de eliciador respondente condicionado. Um exemplo fornecido por Dougher e Hackbert (1994) é o caso de uma cliente que se sentiu melancólica depois de dirigir pela estrada da escola que freqüentou cerca de 20 anos atrás. $O$ relato da cliente indicava que a escola tinha sido um período difícil para ela, quando experımentou situaçōes de rejeição. A visualização do lugar onde essa estimulação aversiva ocorreu era suficiente para eliciar reaçōes emocionais fortes.
III.3. Funções estabelecedoras (Establishing functions).

Uma das características definidoras da depressão é a falta de motivação e uma habilidade diminuída para sentir prazer nas atividades. Dougher e Hackbert (1994) sugerem que, de um ponto de vista analíticocomportamental, a perda da eficiência do reforçador e mudanças na motivação sugerem que operações estabelecedoras lou de supressãol podem estar envolvidas.

Sundberg (1993) esclarece que o conceito de operações estabelecedoras (establishing operations), conforme descrito por Michael (1993), provê a análise do comportamento de um meio de investigar tópicos como motivação sem fazer uso de termos ou construtos cognitivos. De acordo com Hesse (1993) o conceito já estaria incorporado ao vocabulário da análise do comportamento ${ }^{3}$. Operaçōes estabelecedoras: a) aumentam os efeitos de reforçamento de certas consequiências, b) aumentam a probabilidade de respostas que têm produzido reforçadores estabelecidos no passado, c) aumentam a eficiência evocativa de estímulos discriminativos associados aos reforçadores estabelecidos.Operações de supressão teriam o efeito contrário.

O argumento apresentado por Dougher e Hackbert (1994) "é que os eventos ou condiçōes que produzem as baixas taxas de resposta e estados afetivos que são caracteristicos da depressão, também servem como operações estabelecedoras e de supressão"(p.326). Particularmente, esses eventos potencializariam certas contingências e diminuiriam a potência de outras.

Partindo de uma análise que denominaram de "simplista"- Dougher e Hackbert (1994) dividem o mundo em dois tipos de contingênclas. Contingências nāo depressivas seriam aquelas postas em ação (ou que operam) quando um indivíduo não está deprimido (contingências sociais, ocupacionais, recreativas e interpessoais que governam a vida diária). "Quando há um repertório adequado e essas contingências são estabelecidas por um individuo, este se diverte, interage, cria e tira prazer dessas atividades" $(p$ 326). Contingências depressivas seriar aquelas associadas com comportaments depressivo. "Pode haver um aumento em tal comportamento, como chorar, reclamar, 
lamentar-se, culpar-se, esquivar-se socialmente, sono excessivo e assim por diante"(p. 326). Reforçadores estabelecidos podem incluir expressões de simpatia, oferta de ajuda ou assistência, apoio social e a esquiva de atividades e de conseqüências que são geralmente associadas com contingências nãodepressivas. Embora os depressivos possam procurar a simpatia e apoio de outros, eles estão inclinados a evitar situaçōes sociais que exijam um repertório ativo ou interativo de reforçamento. Dependendo do indivíduo, até mesmo atividades fisiológicas básicas como correr e praticar sexo podem perder suas funçōes reforçadoras. Pode ser, contudo, que sejam os aspectos sociais dessas atividades e não as atividades em si que são diminuídas como reforçadores ( Ferster, 1973). Na realidade, dado a escassez de reforçadores disponiveis para muitos depressivos, comer pode se tornar particularmente potencializado. Isso pode explicar porque alguns depressivos comem em excesso, especialmente quando estão sozinhos (Dougher e Hackbert, 1994, p. 326).

De acordo com Dougher e Hackbert (1994), operaçōes estabelecedoras têm uma funçāo importante no efeito sobre estímulos discriminativos relevantes, que poderia explicar dados relatados na literatura voltada para a relaçāo entre cognição e emoçāo, embora ressaltem que, nesses casos, há necessidade de maior investigaçāo. Exemplos desses estudos seriam os conduzidos por Bower $e$ Hellis e Ashbrook ( conforme citados por Dougher e Hackbert, 1994), que têm demonstrado que os estados emocionais ou humores dos indivíduos determinam em grande extensāo os estímulos aos quais eles atendem e lembram: Para estudar esse efeito, sujeitos são primeiramente expostos a um conjunto de procedimentos delineados para induzir um determinado humor. Esses procedimentos incluem hipnose, sugestão verbal ou música indutora de estado de ânimo. Uma tarefa experimental é, então, dada aos sujeitos. Eles podem, por exemplo, ser solicitados a estudar e depois relembrar uma lista de palavras que varia em qualidade afetiva (e.g. triste, feliz) ou para relembrar memórias do início de suas vidas. Sujeitos que são postos em humor deprimido tendem a lembrar palavras $e$ memórias tristes, ao passo que os que são expostos a um amblente relaxado tendem a lembrar palavras e memórias felizes.
Psicólogos cognitivistas têm postulado uma variedade de processos mentais para explicar tais eventos, mas parece que os procedimentos de indução de estados de humor funcionam como operaçōes estabelecedoras e afetam as funçōes evocativas de estímulos relevantes (Dougher e Hackbert, 1994, p.326).

\section{III.4. Processos Verbais.}

Uma questão importante para um estudo comportamental da depressão refere-se aos determinantes do comportamento verbal que caracteriza os depressivos e sua influência sobre outros comportamentos. Tem sido

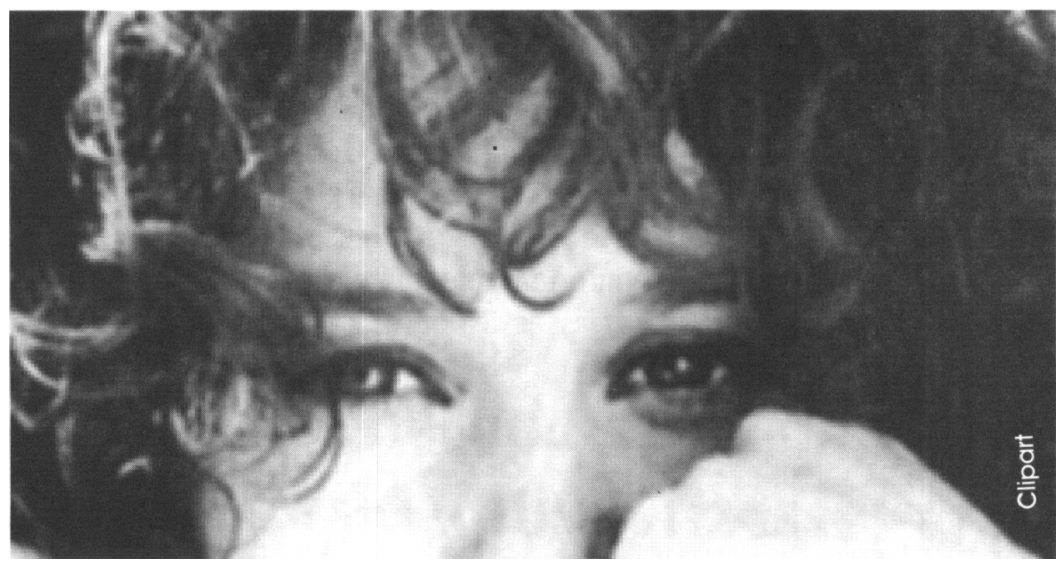

argumentado que, embora processos de condicionamento estejam envolvidos, eles nāo poderiam justificar inteiramente a emissão de novo comportamento verbal ou a aquisição de funçōes psicológicas através do estímulo verbal (cf. Dougher e Hackbert, 1994).

Por exemplo, como é que quando a um indivíduo é dito que experiências de tristeza são um sinal de depressão e que depressão é uma doença, aquele indivíduo conclui que a sua experiência de tristeza é sinal de doença? A lógica da inferência é clara, mas o que são os princípios comportamentais que determinam a inferência lógica? Além disso, como é que a afirmação "eu estou doente" pode evocar um repertório inteiro de comportamento e eliciar certos respondentes? Nāo é provável que o comportamento doentio tenha sido reforçado diferencialmente na presença da palavra doente ou que a palavra doente tenha sido pareada com estímulos incondicionados que eliciam determinados respondentes (Dougher e Hackbert, 1994, p.328, itálico do original). 
Dougher e Hackbert (1994) argumentam que respostas a esse tipo de indagação são sugeridas por recentes pesquisas em equivalência de estímulo e em particular pela transferêncla de função através de classes de equivalência de estímulo. Os que defendem a equivalência de estímulo como o processo comportamental fundamental subjacente à linguagem e outros comportamentos simbólicos, acreditam "que os estímulos verbals adquirem a sua funçāo psicológica em virtude da sua participação em uma relaçāo de equivalência com os eventos que eles significam" "(p. 329, itálico acrescentado).

Por exemplo, imediatamente após ter sido dito que límon é a palavra em espanhol para limão, límon adquire a mesma função de estímulo que a palavra limão (e muitas das mesmas funçōes que os limões apresentam) para o ouvinte. Assim, nāo apenas a pessoa pode responder apropriadamente ao pedido de um límon; a descriçāo de morder um limão irá provavelmente eliciar salivação, assim como a lacrimação facial que ocorre quando sumo de limão é espremido na boca.... Da mesma forma, auto-afirmaçōes como " nāo sou bom", " estou doente", "sou um fracassado", "eu estou deprimido", e "as coisas nunca serāo melhores", exercem uma influência de controle sobre o comportamento (Dougher e Hackbert,1994, p.329).

Argumentam, ainda, que:

Quando "eu" e "fracasso" ou "doente" ou "deprimido" entram numa classe de equivalência, muitas das funçōes associadas a esses descritores negativos aplicam-se ao "eu". Isso pode explicar o desenvolvimento de auto-esquema negativo e de uma auto-verbalização negativa, que caracteriza os depressivos. Contudo, as classes de equivalência, elas próprias, podem ser trazidas sob controle contextual... Desse modo, em alguns contextos, "eu" e uma variedade de termos negativos podem estar em uma classe de equivalência ao passo que, em outros contextos, "eu" está em uma classe com outros descritores, talvez mais positivos. É possível que as variáveis que evocam 0 comportamento depressivo possam servir como estímulos contextuals que controlam a composição das classes de equivalêncla (Dougher e Hackbert, 1994, p. 329).

\section{Conclusão.}

As pesquisas sobre a depressão têm enfatizado os processos biológicos e cognitivos em detrimento da análise das relaçōes amblente-comportamento. Como resultado, a literatura disponí vel sobre o tema não oferece uma explicação adequada para a etiología e tratamento do fenômeno de um ponto de vista analítıco comportamental. A depressão passa a existir a partir de uma interação social dada e, desse modo, pode ser compreendida como um fenômeno cuja dimensāo maior - ou primária - é um processo de interação social. A partir dessa perspectiva, é multidefinida e sempre resultado de uma nomeação regulada pela comunidade. Descrever o comportamento depressivo de um indivíduo é atentar para os padrões de interação que ele estabelece com o ambiente social à sua volta. Assim, a análise funcional parece ser o caminho para que se possa planejar a intervenção. 
Associação Psiquiátrica Americana (1995). Manual Diagnóstico e Estatístico de Transtornos Mentais DSM-IV (Dayse Batista, Trad.). Porto Alegre, Artes Médicas.

Antonuccio, D. O., Danton, W. G. e DeNelsky, G. Y. (1995) Psychotherapy versus medication for depression: Challenging the conventional wisdom with data. Professional Psychology: Research and Practice, 26, 574-585. Retrived from World Wide Web: http://www.apa.org/journals/anton.html.

Beach, S. R. H., Whisman, M. A \& O'Leary, K. D. (1994). Marital therapy for depression: theorical foundations, current status, and future directions. Behavior Therapy, 25, 345-372.

Beck, A.T., Rush, A.J., Shaw, B.F. \& Emery, G. (1982). Terapia cognitiva da depressāo (Vera Ribeiro, Trad.). Rio de Janeiro, Zahar. (trabalho original publicado em 1979).

Casey, D.E.(1994). A busca de equilíbrio entre segurança e eficácia: experiência com IRSR sertralina. Jornal Brasileiro de Psiquiatria, 43, 61S-68S.

Cunha, R. N. (1995). Mottvação e Comportamento. Temas em Psicologia (3), 11-18.

Dougher, M. J. \& Hackbert, L. (1994).A behavioranalitic account of depression and a case report using acceptance-based procedures. The Behavior Analiyst, 17, 321-334.

Ferreira, A B. H. (1986). Novo Dicionário da Língua Portuguesa. $2^{\mathrm{a}}$ Ediçăo. Rio de Janeiro, Nova Fronteira.

Guilhardi, H. J. e Oliveira, W. (1997). Linha de base mültipla: possibilidades e limites deste modelo de controle de variáveis em situação clínica. Em Banaco, R.A. (Org.). Sobre o Comportamento e Cognição (pp. 348-384).São Paulo, ARBytes Editora, Ltda.

Harris, B. (1994). Biological and hormonal aspects of postpartum depressed mood: working towards strategies for prophylaxis and tretment. British Journal of Psychiatry, 164, 288-292.

Hayes, S, C \& Follette, W.C. (1992). Can functional analysis provide a substitute for syndrome classification? Behavioral Assessment, 14, 345-365. Hesse, B. (1993).Establishing operations revisited. The Behavior Analyst, 16, 215-217.

Hunziker, M. H. L. (1982). Consideraçöes metodológicas sobre o estudo da incontrolabilidade. Psicologia, 8, 61-77.

Hunziker, M. H. L. (1993). Desamparo aprendido: um modelo animal de depressão? Psicologia: Teoria e Pesquisa, 9, 487-498.

Hollon, S. D. \& Carter, M. M. (1994). Depression in adults. Em Craighead, L.W.Craighead, W. E. , Kazdin, A. E. \& Mahoney, M. J.(Orgs).Cognitive and behavioral interventions. An empirical approach to mental health problems ( pp. 89-104).
Hollon, S. D. \& Carter, M. M. (1994). Depression in adults. Em Craighead, L.W.Craighead, W. E. , Kazdin, A. E. \& Mahoney, M. J.(Orgs).Cognitive and behavioral interventions. An empirical approach to mental health problems (pp. 89-104).

Jarrett, R.B. \& Nelson, R. O. (1987). Mechanisms of chance in cognitive therapy of depression., Behavior Therapy ,18, 227-241.

Kendler. K. S., Neale, M. C., Kessler, R. C., Heath, .A. C. \& Eaves, L. J. (1994). The clinical characreristics of major depression as indices of the familiar risk to ilness. British Journal of Psychiatry, 165, 66-72.

Koerner, K., Prince, S., Jacobson, N. S.(1994). Enhancing the treatment and prevention of depression in women: the role of integrative behavioral couple therapy. Behavior Therapy, 25, 373-390.

Machado, J. P. (1977). Dicionário Etimológico da

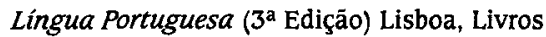
Horizonte.

Malerbi, F. E. K.e Matos, M. A. (1992). A análise do comportamento verbal e a aquisição de repertórios autodescritivos de eventos privados.Psicologia: Teoria e Pesquisa, 8, 407-421.

Michael, J. (1993). Estabilishing operations. The Behavior Analyst, 16, 191-206.

Moore, J. (1995). Radical behaviorism and the subjective-objective distinction. The Behavior Analyst, 18 (1), 33-49.

Nishith, P., Hearst, D. E., Mueser, K. T. \& Foa, E. B. (1995). PTSD and major depression: metodological and treatment considerations in a single case design. Behavior Therapy, 26, 319-335.

Pardoen, D., Bauwens, A, Martin, T.F \& Mendlewicz, J. (1993).Self-esteem in recovered bipolar and unipolar out-patients. British Journal of Psychiatry, 163, 755762 .

Piccinelli, M. \& Wilkinson, G. (1994). Outcome of depression in psychiatric settings. British Journal of Psyquiatry, 164, 297-304.

Preskorn, S. (1994). Farmacoterapia no tratamento da depressāo: farmacocinética comparativa da fluoxetina, paroxina e sertralina. Jornal Brasileiro de Psquiatria, 69S-75S.

Priebe, S. \& Gruyters, T. (1995). The importance of the first three days: Predictors of treatment outcome in depressed in-patient. British Journal of Clinical Psychology, 34, 229-236.

Seligman, M.E.P. (1992). Helplessness. On development, depression and death. New York, W.H. Freeman and Company (Trabalho original publicado em 1975).
Referências bibliográficas 
Referências bibliográficas
Skinner, B. F. (1945). The operational analysis of psychological terms. Psychological Review, 52, 270277.

Skinner, B. F. (1974). About Behaviorism. New York: Alfred A. Knopf.

Skinner, B. F. (1989). Questöes recentes na análise comportamental (Anita Nery, Trad.) Campinas:Papirus

Skinner, B. F. ( 1992 ). Verbal Behavior. Massachusetts: Copley Publishing Group (Trabalho original publicado em 1957).

Spangler, D.L., Simons, A D., e Thase, M. E.(1997). Response to cognitive-behavioral therapy in depression: effects of pretreatment cognitive dysfunctional and life stress. Journal of Consulting and Clinical Psychology, $65,568-575$.

Sundberg, M. L. (1993).The application of establishing operations. The behavior Analyst, 16, 211-214.
Surtees, P. G. \& Barkley, C. (1994). Future imperfect: the long term outcome of depression. British Journal of Psychiatry, 164, 327-341.

Thompson,C. (1994). Tratamento da depressão em situaçöes reais: resultados de ensaios clínicos em larga escala. Jornal Brasileiro de Psquiatria, 43, 76S$80 \mathrm{~s}$

Tourinho,E.Z. (1997a). Eventos privados em uma ciência do comportamento.Em Banaco, R.A. (Org.) Sobre o Comportamento e Cognição (pp.174-187).São Paulo, ARBytes Editora, Ltda.

Tourinho,E.Z. (1997b). Privacidade, comportamento e $o$ conceito de ambiente interno. Em Banaco, R.A. (Org.). Sobre o Comportamento e Cognição (pp. 217 229).São Paulo, ARBytes Editora, Ltda.

Turner, R. (1994). Qualidade de vida: experiência com Sertralina. Jornal Brasileiro de Psiquiatria, 43, 81S$86 \mathrm{~S}$. 